\title{
OsMS188 Is a Key Regulator of Tapetum Development and Sporopollenin Synthesis in Rice
}

Yu Han, Si-Da Zhou, Jiong-Jiong Fan, Lei Zhou, Qiang-Sheng Shi, Yan-Fei Zhang, Xing-Lu Liu, Xing Chen, Jun Zhu ${ }^{*}$ and Zhong-Nan Yang ${ }^{*}$ (i)

\begin{abstract}
Background: During anther development, the tapetum provides essential nutrients and materials for pollen development. In rice, multiple transcription factors and enzymes essential for tapetum development and pollen wall formation have been cloned from male-sterile lines.

Results: In this study, we obtained several lines in which the MYB transcription factor OsMS188 was knocked out through the CRISPR-Cas9 approach. The osms188 lines exhibited a male-sterile phenotype with aberrant development and degeneration of tapetal cells, absence of the sexine layer and defective anther cuticles. CYP703A3, CYP704B2, OsPKS1, OsPKS2, DPW and ABCG15 are sporopollenin synthesis and transport-related genes in rice. Plants with mutations in these genes are male sterile, with a defective sexine layer and anther cuticle. Further biochemical assays demonstrated that OsMS188 binds directly to the promoters of these genes to regulate their expression. UDT1, OsTDF1, TDR, bHLH142 and EAT1 are upstream regulators of rice tapetum development. Electrophoretic mobility shift assays (EMSAs) and activation assays revealed that TDR directly regulates OsMS188 expression. Additionally, protein interaction assays indicated that TDR interacts with OsMS188 to regulate downstream gene expression.
\end{abstract}

Conclusion: Overall, OsMS188 is a key regulator of tapetum development and pollen wall formation. The gene regulatory network established in this work may facilitate future investigations of fertility regulation in rice and in other crop species.

Keywords: Rice, Tapetum, Pollen sexine, Sporopollenin, Transcription factor

\section{Background}

Rice (Oryza sativa L.) is one of the world's most important agricultural crop species and supports the nutritional requirements of more than half of the global population. Heterosis from hybrid breeding significantly increases agricultural yields of rice and other crop species (Chen and Liu 2014). The use of male-sterile plants, which serve as necessary breeding materials, constitutes a convenient approach for producing hybrid varieties. A large

\footnotetext{
* Correspondence: zhujun78@shnu.edu.cn; znyang@shnu.edu.cn Shanghai Key Laboratory of Plant Molecular Sciences, College of Life Sciences, Shanghai Normal University, 100 Guilin Road, Shanghai 200234, China
}

(C) The Author(s). 2021 Open Access This article is licensed under a Creative Commons Attribution 4.0 International License, which permits use, sharing, adaptation, distribution and reproduction in any medium or format, as long as you give appropriate credit to the original author(s) and the source, provide a link to the Creative Commons licence, and indicate if changes were made. The images or other third party material in this article are included in the article's Creative Commons licence, unless indicated otherwise in a credit line to the material. If material is not included in the article's Creative Commons licence and your intended use is not permitted by statutory regulation or exceeds the permitted use, you will need to obtain permission directly from the copyright holder. To view a copy of this licence, visit http://creativecommons.org/licenses/by/4.0/. to date, and related genes have been cloned. Most of these genes play essential roles in tapetum development and pollen formation.

The tapetum is the innermost layer of the four sporophytic layers of the anther wall. The tapetal layer is in directly contact with developing gametophytes and provides necessary materials and nutrients for microspore development (Mariani et al. 1990; McCormick 1993; Ariizumi and Toriyama 2011). Several transcription factors essential for tapetum development have been cloned from male-sterile lines of rice. Undeveloped Tapetum1 (UDT1) (Jung et al. 2005), Tapetum Degeneration 
Retardation (TDR) (Li et al. 2006), ETERNAL TAPE TUM 1/DELAYED TAPETUM DEGENERATION (EAT1/DTD) (Niu et al. 2013; Ji et al. 2013) and INTE RACTING PROTEIN 2/bHLH142 (TIP2/bHLH142) (Fu et al. 2014; Ko et al. 2014) encode transcription factors of the bHLH family. BHLH142 acts downstream of UDT1 but upstream of TDR and EAT1 in tapetum development (Fu et al. 2014; Ko et al. 2014). OsTDF1 encodes an R2R3-MYB-family protein (Cai et al. 2015). These genes play an essential role in early tapetum development in rice. Plants with mutations in these transcription factors exhibit a similar phenotype in which abnormally vacuolated and enlarged tapetal cells occupy the locule space during anther development. PTC1 encodes a PHD-finger protein that functions in the late stage of tapetum development, at which time the anther locule forms in the mutants (Li et al. 2011).

The tapetum directly provides materials for pollen wall formation and nutrients for pollen development. Several tapetum genes involved in pollen wall formation have been cloned from male-sterile lines of rice. CYP703A3 and CYP704B2 belong to the cytochrome P450 family and catalyse the in-chain 7-hydroxylation of lauric acid and the $\omega$-hydroxylation of fatty acids with 16 and 18 carbon chains, respectively (Li et al. 2010; Yang et al. 2014). OsPKS1 and OsPKS2 condense fatty acyl-CoA into triketide and tetraketide a-pyrones, respectively, which are predicted to be components of the sporopollenin precursor (Shi et al. 2018; Zou et al. 2018). OsACOS12 encodes an acyl-CoA synthetase that esterifies fatty acids to fatty acyl-CoA in the plastids of the tapetum (Li et al. 2016; Yang et al. 2017). DPW encodes a fatty acid reductase that converts the palmitoyl-acyl carrier protein to fatty alcohols, producing sporopollenin monomers (Shi et al. 2011). The resultant sporopollenin precursors are predicted to be transported to anther locules by the membrane transport protein ABCG15 (Qin et al. 2013). Because the above genes are expressed in the tapetum, elucidation of the regulatory mechanism involving tapetal transcription factors and the expression of pollen wall-related genes is important for understanding pollen formation. A previous study proposed that the expression of several sporopollenin-related genes, such as $C Y P 704 B 2$ and $C Y P 703 A 3$, was regulated by TDR in rice, which is considered a key transcriptional regulator in pollen wall formation (Shi et al. 2015). However, the rice tapetal genetic pathway includes other transcription factors. The mechanisms of these regulators and downstream targets in pollen wall formation require further genetic and biochemical validation.

A previous investigation showed that the knockdown of OsMS188 (LOC_Os04g39470), which encodes a MYB transcription factor in rice, resulted in defective pollen formation and reduced fertility (Zhang et al. 2010). Here, we obtained OsMS188 knockout lines through the CRIS PR-Cas9 approach; these lines were completely male sterile. The osms 188 mutants presented aberrant vacuolized tapetal cells, an absent sexine layer and a defective anther cuticle. The expression of multiple sporopollenin genes is directly regulated by OsMS188. Therefore, OsMS188 is a key regulator of tapetum development and pollen wall and cuticle layer formation in rice. Additionally, OsMS188 is directly regulated by and interacts with TDR to activate the expression of downstream targets, which extends the tapetal regulatory network. The elucidation of this genetic pathway not only is helpful for understanding anther development but also can provide clues for further investigation of fertility regulation.

\section{Results}

Knockout of OsMS188 Causes Complete Male Sterility

A knockout mutant of OsMS188 was obtained via the CRISPR-Cas9 approach in which the first exon of OsMS188 (LOC_Os04g39470) in wild type Nipponbare was targeted (Fig. 1a). A total of 26 transgenic lines were obtained. Among these transgenic lines, two lines exhibiting an adenosine insertion (osms188-1) and a guanine deletion (osms188-2) in their first exons were identified. These mutations led to a frameshift of OsMS188 with a premature stop codon in these two lines (Fig. 1b). Compared with the fertile phenotype of the wild type (Fig. 1c, $\mathrm{f}$ and $\mathrm{g}$ ), the phenotype of both transgenic lines was male sterile, and the plants had white, shrunken anthers (Fig. $1 \mathrm{~d}, \mathrm{i}, \mathrm{j}, \mathrm{e}, \mathrm{l}$ and $\mathrm{m})$. Alexander staining showed that the osms188 anthers contained no mature pollen grains and presented only a few degenerated pollen remnants (Fig. $1 \mathrm{~h}, \mathrm{k}$ and $\mathrm{n}$ ). To confirm whether the male-sterile phenotype of the transgenic lines was caused by the mutation of OsMS188, we crossed these lines with the wild type. The F1 plants showed normal fertility, and the segregation ratio of the fertile and sterile phenotype in the F2 generation was approximately 3:1 (202:82, $\chi^{2}{ }_{3: 1}=$ 2.0704). We sequenced the OsMS188 locus in the malesterile lines in the F2 population. This locus had a mutation in all the lines. Taken together, these results demonstrate that the target mutations of OsMS188 caused male sterility in the transgenic lines.

\section{The Sexine Layer Is Absent in the osms188 Mutant}

To identify the specific defect in pollen development, cytological analyses were performed. Scanning electron microscopy (SEM) showed that the anthers of osms188 shrank and were much smaller than those of the wild type (Fig. 2a and d). The surface of the wild-type anthers was covered with a normal cuticle layer (Fig. 2b). However, the reticulate cuticle layer was absent on the surface of the anthers of osms188 (Fig. 2e), which is consistent with the characteristics of other 


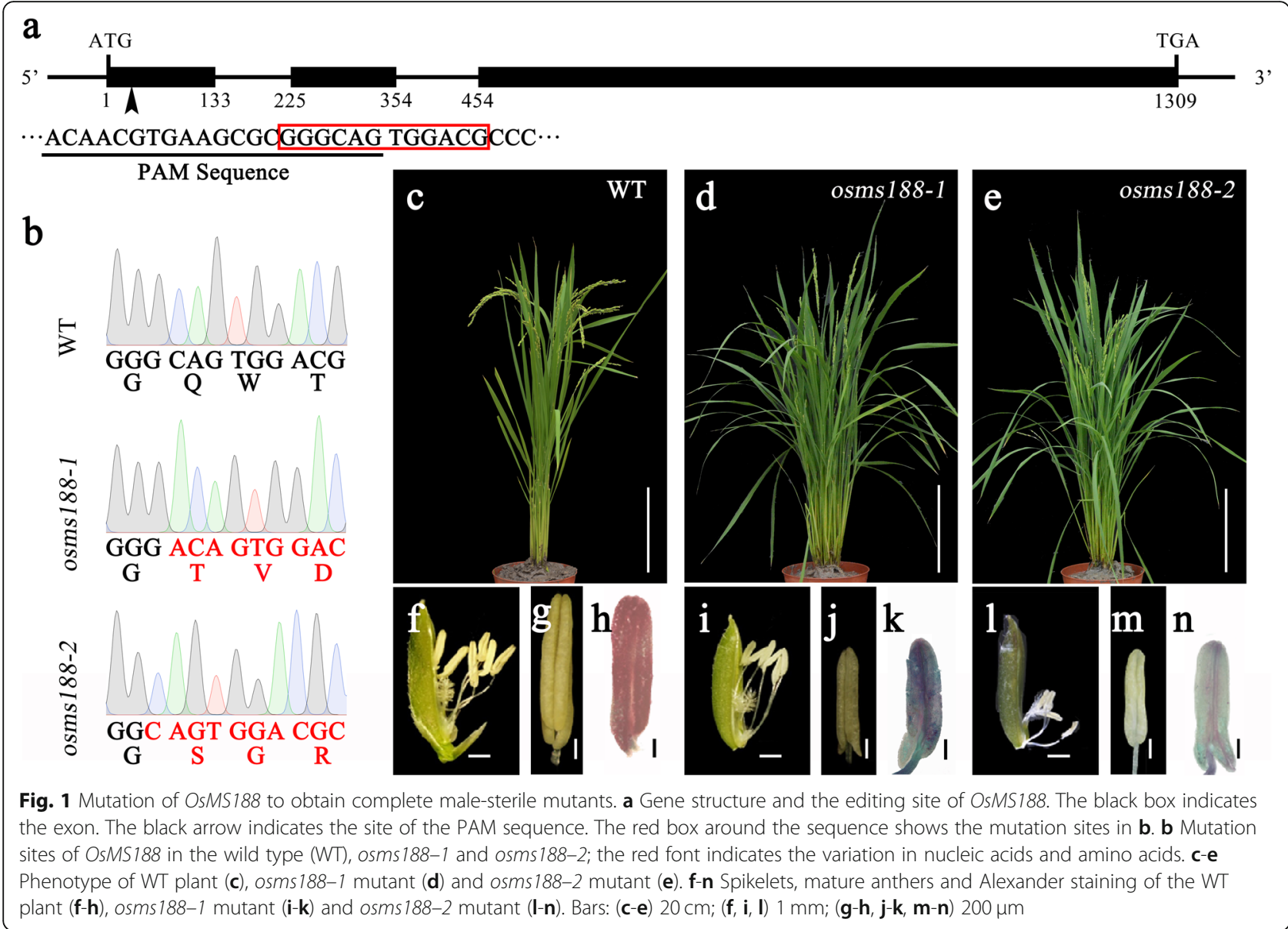

sporopollenin-related mutants (Li et al. 2010; Shi et al. 2011; Yang et al. 2014; Li et al. 2016). In rice, anther development is divided into 14 stages according to morphological characteristics (Zhang and Wilson 2009). Semi-thin sections showed that no detectable differences were observed between the osms 188 and wild type plants in terms of anther development before stage 8 . However, the tapetal cells became irregularly vacuolated after stage 8 (Fig. S1). To illustrate the detailed defect in pollen development in this mutant, we performed transmission electron microscopy (TEM). The results showed that the reticulate cuticle layer on the anther surface in osms 188 was obviously thinner than that in the wild type (Fig. 2c and $\mathrm{f}$ ). At stage 9, TEM showed that Ubisch bodies initially presented on the internal surface of the wild type tapetum (Fig. 2g), and probacular materials were deposited outside the microspores (Fig. 2k). At stage 10, abundant Ubisch bodies had been clearly secreted on the internal surface of the tapetum (Fig. 2h). Additionally, the sexine layer of the pollen wall with tectum and baculum structures gradually formed in the wild type (Fig. 21 and $\mathrm{m}$ ). However, at stage 9, the tapetal cytoplasm of osms188 was filled with large vacuoles without Ubisch bodies, and probacular materials were not observed on the surface of osms188 microspores (Fig. $2 \mathrm{i}$ and n). During the late stages, the tapetal protoplasts of osms 188 were largely degenerated, and no Ubisch bodies accumulated (Fig. 2j). Most developing microspores were also degraded in the osms 188 mutant, and only a few microspore residues remained. The sexine layer was completely absent on the surface of these residues (Fig. 2o and $\mathrm{p}$ ).

\section{The PCD Process Is Altered in the Tapetal Cells of the osms 188 Mutant}

The tapetum undergoes cellular degradation by programmed cell death (PCD) during the late stage of anther development. To understand whether tapetum PCD is affected in osms188, a TUNEL assay was performed. No fluorescence signals were observed in the anthers of either wild type or osms 188 plants during the meiosis stage (Fig. 3a and e). In the wild type, TUNEL signals were initially detected in tapetal cells at the tetrad stage (Fig. 3b), and their signals became stronger at the microspore release stage (Fig. 3c). At stage 10 , the signals were still visible, although they were weaker than those in the previous two stages (Fig. 3d). In the osms188 mutant, the TUNEL signals 

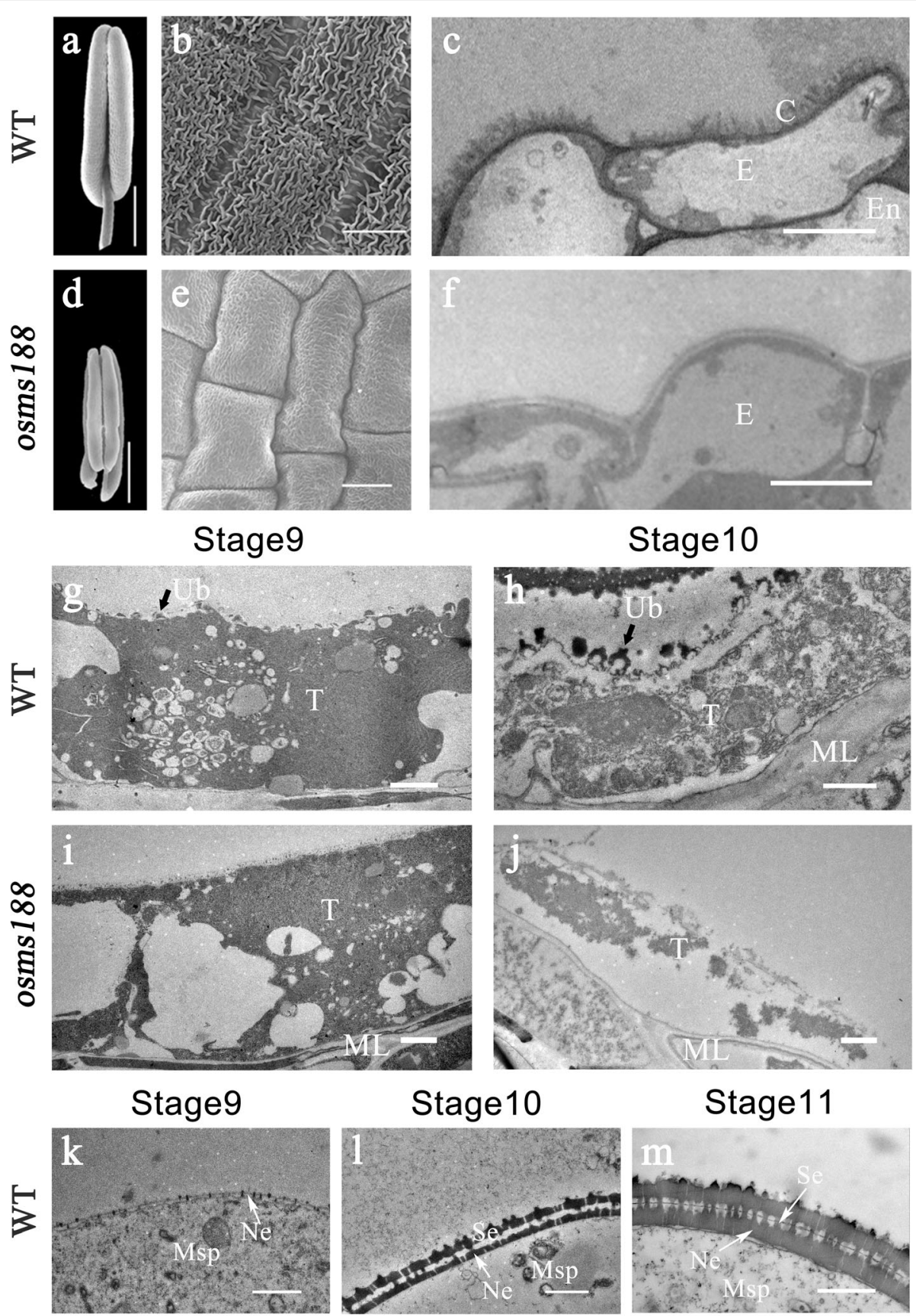

\section{Stage11}
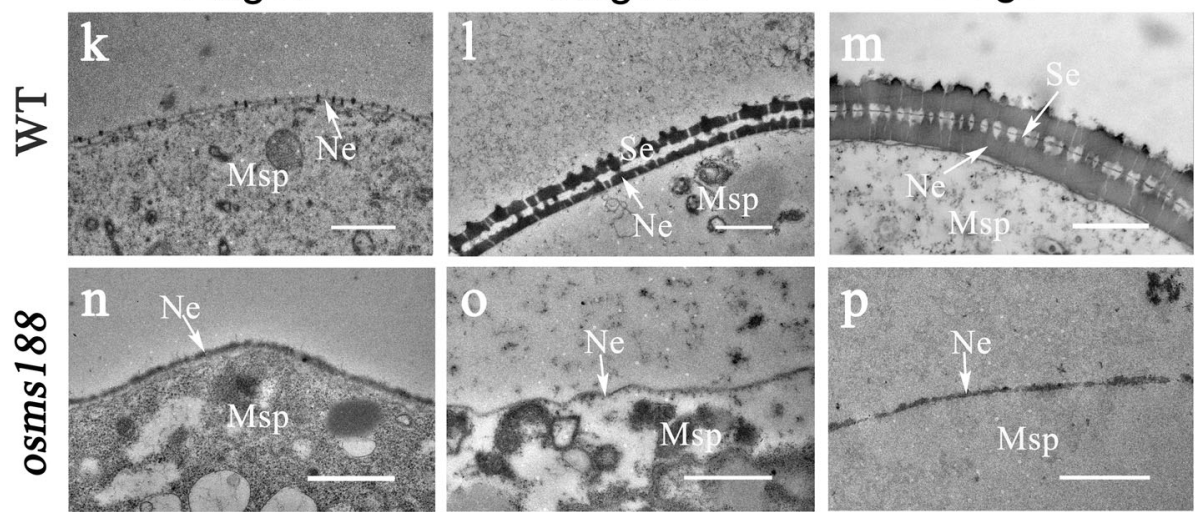

Fig. 2 Electron micrographs of anthers and pollen grains of the WT and osms188 mutant. SEM observations showing the anther and pollen development of the WT (a-b) and osms188 (d-e). Anther morphology of the WT (a) and osms188 (d) and the epidermal surfaces of WT (b) and osms188 (e) anthers. TEM observations of tapetum development and sexine formation of the WT ( $\mathbf{c}, \mathbf{g}, \mathbf{h}, \mathbf{k}, \mathbf{I}, \mathbf{m})$ and osms $188(\mathbf{f}, \mathbf{i}, \mathbf{j}, \mathbf{n}, \mathbf{o}, \mathbf{p})$. Cuticle layer of the WT (c) and osms 188 (f). The tapetal cells of the WT (g) and osms188 (i) at stage 9 and the tapetal cells of the WT (h) and osms 188 (j) at stage 10. Pollen wall formation in the WT $(\mathbf{k}, \mathbf{l}, \mathbf{m})$ and osms188 (n, o, p) during stages 9-11. C, cuticle; E, epidermis; En, endothecium; ML, middle layer; Msp, microspore; Ne, nexine; Se, sexine; T, tapetum; Ub, Ubisch body. Bars: (a, d) $500 \mu \mathrm{m}$; (b, e) $20 \mu \mathrm{m} ;$ (c, f) $5 \mu \mathrm{m} ;(\mathbf{g}-\mathbf{l}, \mathbf{o}-\mathbf{p}) 1 \mu \mathrm{m}$; (m, n) $0.5 \mu \mathrm{m}$ 


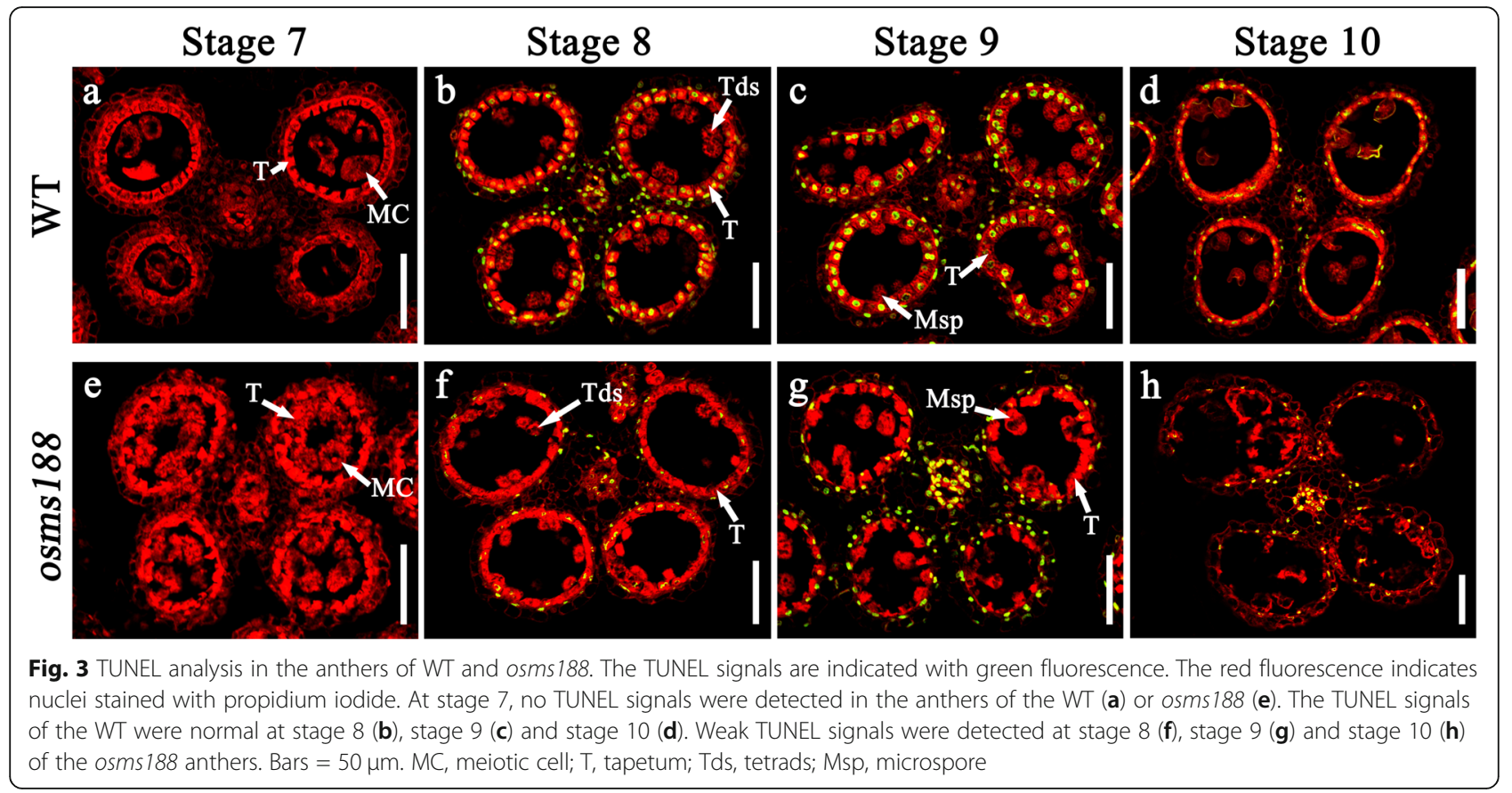

were very weak in the aberrant tapetal cells at all these stages (Fig. 3f, g and h). These observations demonstrate that tapetum PCD in osms188 is obviously slower than that in the wild type, suggesting that OsMS188 is involved in regulating tapetum degeneration during anther development.
OsMS188 Is Highly Expressed in Tapetal Cells during Anther Development

Cytological observations have revealed that OsMS188 is essential for tapetum development and pollen wall formation in rice. RNA in situ hybridization was performd to understand OsMS188 expression in the anthers in
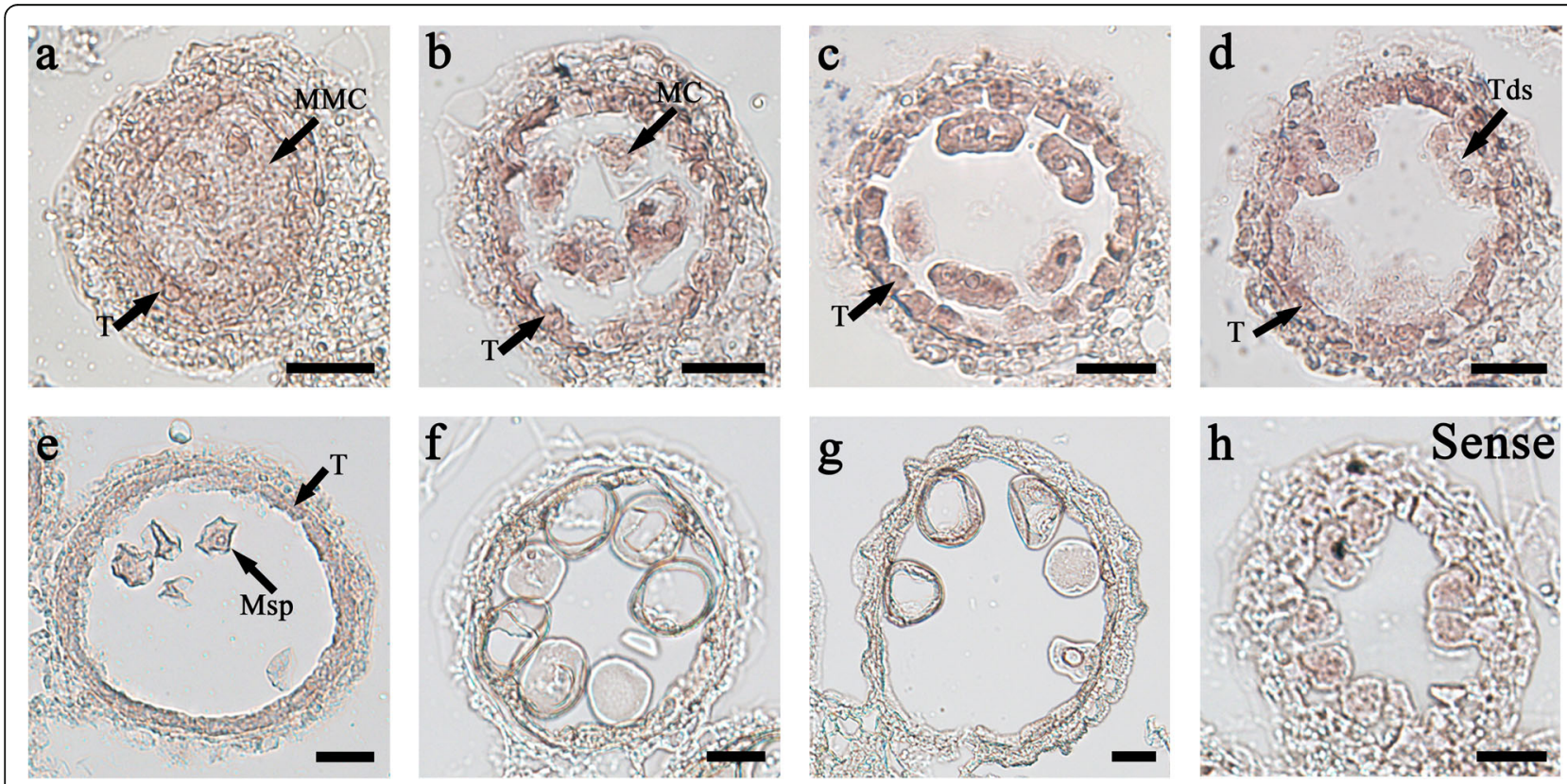

Fig. 4 In situ analysis of OsMS188 expression in wild-type anthers at different developmental stages. In situ hybridization of OsMS188 transcripts at stage $6(\mathbf{a})$, stage $7(\mathbf{b})$, stage $8 \mathrm{a}(\mathbf{c})$, stage $8 \mathrm{~b}(\mathbf{d})$, stage $9(\mathbf{e})$, stage $10(\mathbf{f})$ and stage $11(\mathbf{g})$ anthers with an OsMS188 antisense probe. The anthers at stage $8 \mathrm{~b}(\mathbf{h})$ hybridized to an OsMS188 sense probe. MMC, microspore mother cell; MC, meiotic cell; Msp, microspore; T, tapetum; Tds, tetrads. Bars $=20 \mu \mathrm{m}$ 
detail. Transcripts of OsMS188 were initially detected at stage 6 (Fig. 4), and their abundance gradually increased in tapetal and meiocyte cells at stage 7 (Fig. 4b). At the tetrad stage, the OsMS188 transcript abundance peaked in the tapetal cells (Fig. 4c and d). After microspore release, the expression of OsMS188 radically decreased in the tapetum and microspores (Fig. 4e, $\mathrm{f}$ and $\mathrm{g}$ ). In the control, the sense probe exhibited only background signals at the tetrad stage (Fig. 4h). The expression pattern of OsMS188 in tapetal cells is in accordance with the timing of pollen wall formation.

\section{TDR Directly Regulates OsMS188}

UDT1, OsTDF1, TDR, bHLH142, and EAT1 encode transcription factors that are essential for rice tapetum development (Jung et al. 2005; Li et al. 2006; Niu et al. 2013; Ko et al. 2014; Cai et al. 2015). We analysed the relationship between OsMS188 and these five transcription factors. Both RT-PCR and qRT-PCR analyses showed that OsMS188 expression was significantly downregulated in all the plants with mutations in these genes (Fig. 5a; Fig. S2). Among these transcription factor-coding genes, OsTDF1 encodes a MYB transcription factor, and the other four encode bHLH transcription factors. Since UDT1 encodes an upstream regulator of $O s T D F 1$, it is unlikely to be a direct regulator of OsMS188. Previous work showed that the expression of OsMS188 was significantly reduced in ostdf1 and that of $T D R$ and $E A T 1$ was also reduced to some extent, indicating that these genes are downstream of OsTDF1 (Cai et al. 2015). TDR, bHLH142, and EAT1 encode bHLH transcription factors. We sought to determine which transcription factors could directly regulate the expression of OsMS188. The promoter region of OsMS188 (-1142 and -1097) contains two core motifs of bHLH cis-elements (CANN TG) (Fig. 5b). The bHLH142, EAT1 and TDR proteins were expressed in and purified from Escherichia coli Rosetta. EMSAs showed that the recombinant TDR proteins could bind to DNA probes containing the 'CANNTG' core motif. Unlabelled probes competed for DNA binding when applied at a 5-, 10-, 20-, 50-, 100- or 200-fold concentration (Fig. 5c). However, the abundance of the shifted bands could not be reduced by unlabelled competitor probes when the bHLH142 and EAT1 proteins were incubated together with the probe for the OsMS188 promoter (Fig. 5d and e). These data show that TDR, rather than bHLH142 or EAT1, directly binds to the promoter of OsMS188 in vitro. A transient expression assay using Arabidopsis protoplasts was performed to determine whether TDR could activate the expression of OsMS188. We generated constructs containing the coding DNA sequence (CDS) of TDR driven by the cauliflower mosaic virus (CaMV35S) promoter (p35s::TDRnos) as an effector, while the firefly luciferase (LUC) reporter gene was driven by the OsMS188 promoter together with the 35S::Renilla gene as a reporter
(pOsMS188::LUC). A construct containing only the $35 \mathrm{~S}$ promoter and the terminator was used as a negative control (p35s::nos). When p35s::TDRnos and pOsMS188::LUC were cotransformed into protoplasts, LUC luminescence significantly increased compared with the background level in the negative control (Fig. $5 \mathrm{f}$ and g). These results indicated that TDR directly binds the promoter of OsMS188 to regulate its expression during anther development.

\section{OsMS188 Interacts with TDR}

MYB family members frequently interact with bHLH transcription factors to regulate downstream genes during plant growth and development (Koes et al. 2005; Appelhagen et al. 2011). Protein interaction assays were subsequently performed to analyse whether TDR interacts with OsMS188. A previous study showed that the C-terminus of AtMS188 contains an activation domain (Xiong et al. 2016). We generated several constructs with truncations of different lengths of the C-terminal region to identify the activation domain in OsMS188 (Fig. 6a). Yeast two-hybrid assays showed that AH109 strains with the full-length CDS of OsMS188 could grow on selective media lacking Leu, His and adenine. However, when the last 14 amino acids were deleted, the yeast could not grow on selective media, indicating that the activation domain of OsMS188 was located within those 14 amino acids at the C-terminus (Fig. 6a and b). We subsequently generated a construct containing the OsMS188 CDS without this fragment (14 residues at the C-terminus) (BK-OsMS188 $\Delta$ C) to analyse whether it could interact with TDR. The results showed that only the yeast containing AD-TDR and BK-OsMS188 $\triangle \mathrm{C}$ was able to grow on $\mathrm{SD}^{-\mathrm{Leu} /-\mathrm{Trp} / \text {-His/-ade }}$ selective media (Fig. 6c). These results indicated the existence of protein-protein interactions between OsMS188 and TDR. The interaction between these two proteins was further validated using a firefly luciferase complementation imaging (LCI) assay in tobacco. OsMS188 and TDR were fused to the N-terminal (NLUC) and C-terminal (CLUC) domains of LUCIFERASE, respectively. The results showed that the cotransfection of OsMS188-NLUC together with TDR-CLUC produced strong luciferase activity, while the infiltration of the individual OsMS188NLUC/TDR-CLUC vectors together with the corresponding empty construct failed to produce a visible signal (Fig. $6 \mathrm{~d}$ ). Both the yeast two-hybrid and LCI assays suggested interactions occur between OsMS188 and TDR.

\section{OsMS188 Regulates the Expression of Several Sporopollenin Synthesis-Related Genes}

OsPKS1, OsPKS2, DPW, DPW2, DPW3, CYP703A3, CYP704B2 and TKPR1 have been reported to be involved in sporopollenin synthesis in rice ( $\mathrm{Li}$ et al. 2010; Shi et al. 2011; Yang et al. 2014; Xu et al. 2017; Zou 


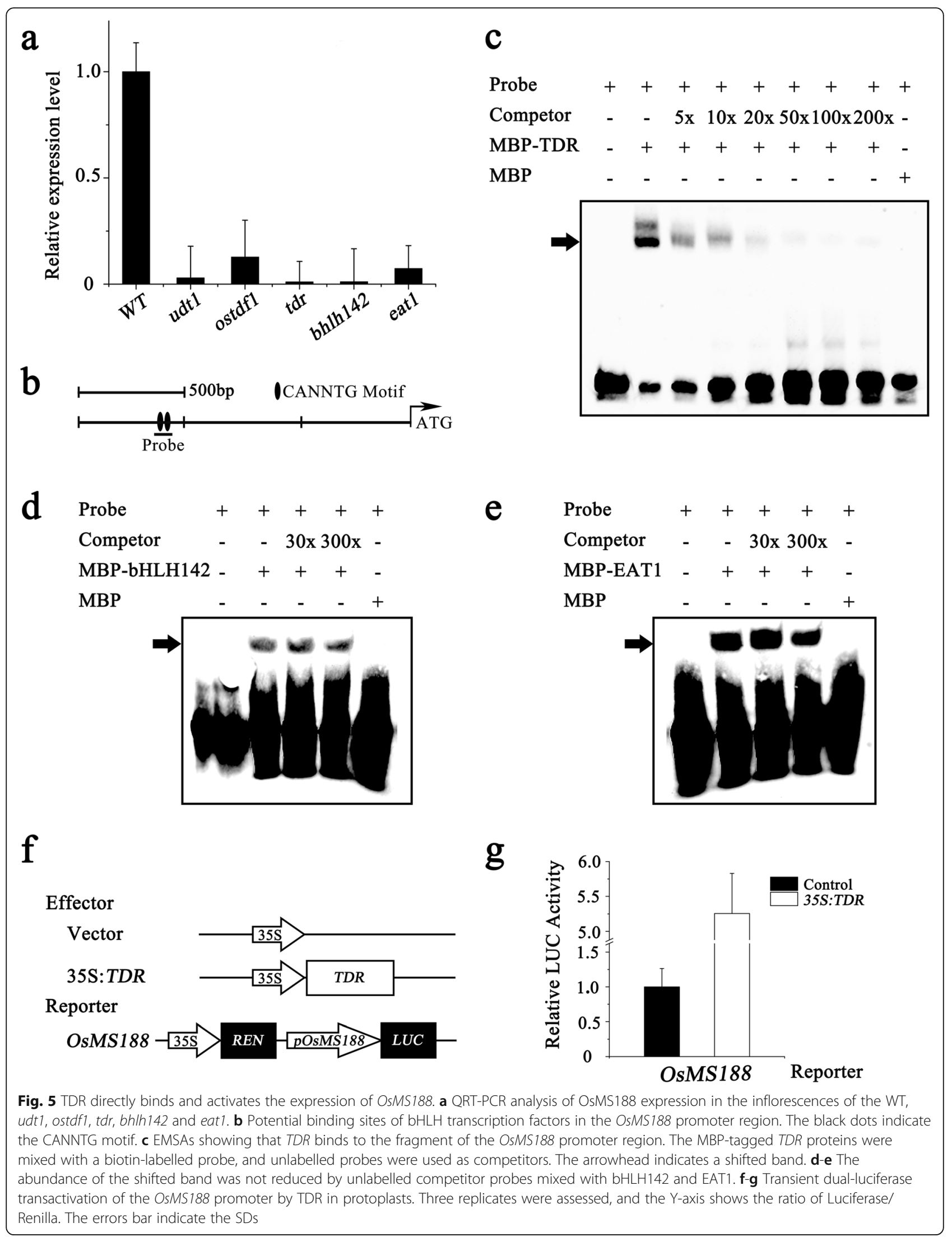




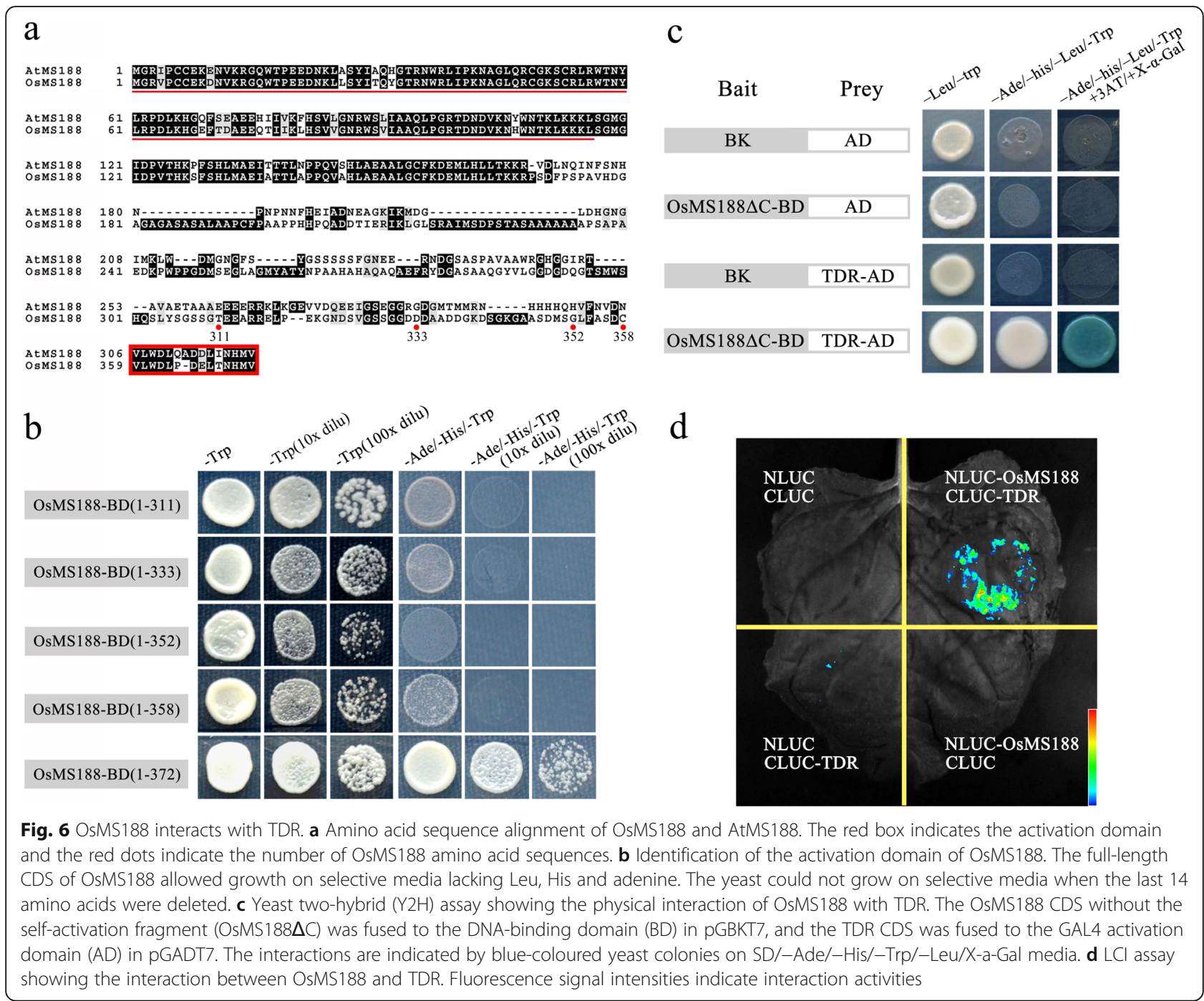

et al. 2017; Shi et al. 2018; Zou et al. 2018; Xu et al. 2019; Mondol et al. 2020). Moreover, ABCG15 and OsABCG26 are involved in sporopollenin precursor transport (Qin et al. 2013; Wu et al. 2014; Zhao et al. 2015). QRT-PCR analyses showed that the expression of OsPKS1, DPW, CYP703A3, CYP704B2, TKPR1, ABCG15 and OsABCG26 was severely downregulated in the osms 188 mutant; however, the expression of OsPKS 2 increased 4.5-fold in the osms188 mutant (Fig. 7a; Fig. S3). In the $t d r$ mutants, the expression of all these genes was also downregulated (Fig. 7a). As OsMS188 is a member of the MYB transcription factor family, the core motif of MYB cis-elements (AACC) is present in the promoter region of the above genes. We selected $C Y P 703 A 3$, CYP704B2, OsPKS1, OsPKS2, DPW and ABCG15 to analyse their relationship with OsMS188. EMSAs involving the purified recombinant MBP-OsMS188 proteins (Fig. S4) showed that OsMS188 could bind to specific probes containing the AACC sequences in these genes, and the shifted band was negatively correlated with the different concentrations of the competitive probe (Fig. 7b, c, d, e, f and $g$ ).

In addition, we assessed whether tapetal transcription factors could activate the expression of these sporopollenin-related genes through a protoplast transient expression system. We generated p35s::OsMS188nos and p35s::TDRnos as effectors and $p C Y P 703 A 3-L U C$, pCYP704B2-LUC, pOsPKS1-LUC, pOsPKS2-LUC, pDPW-LUC and $p A B C G 15-L U C$ as reporters and cotransformed them into Arabidopsis protoplasts. The results showed a weak background fluorescence signal in each control group. When reporter constructs with p35s::TDRnos were cotransformed, LUC activity was hardly induced. However, the amount of fluorescence significantly increased when p35s::OsMS188nos together with these reporters was added. For the cotransformation of the reporter with both $p 35 s:: O s M S 188 n o s$ and p35s::TDRnos, the LUC activity did not obviously 

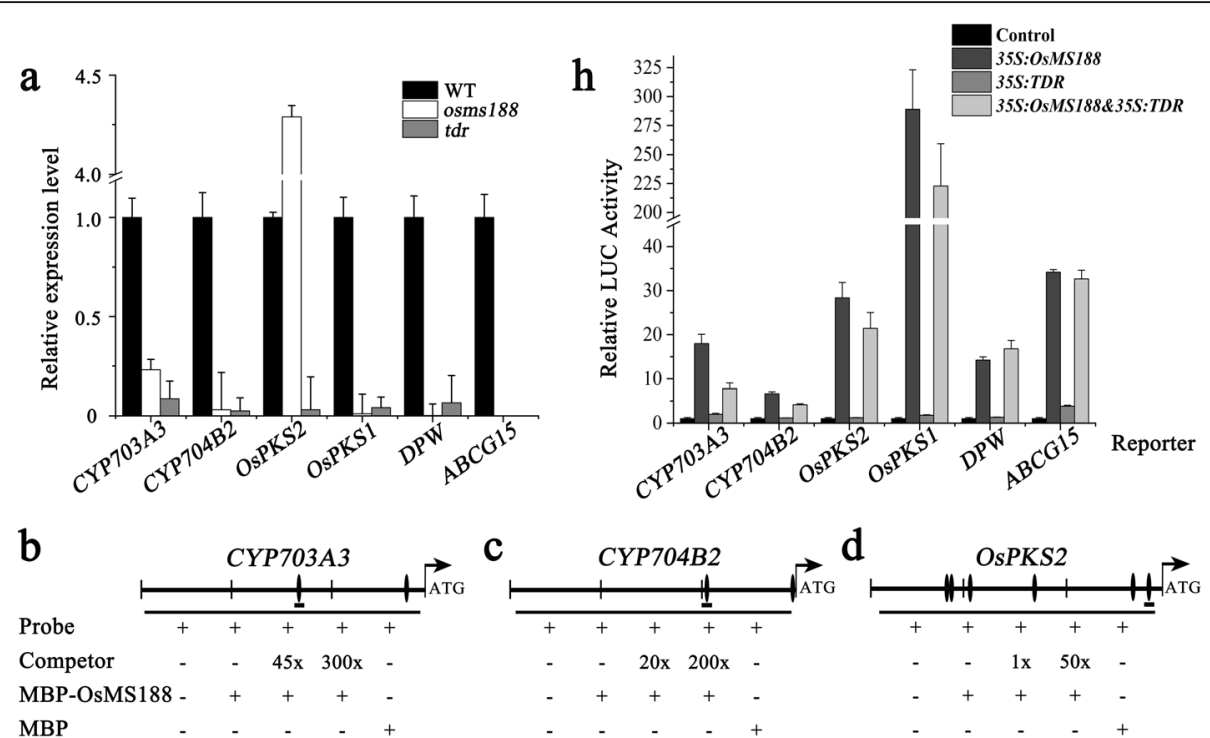

MBP-OsMS188 - +++

MBP
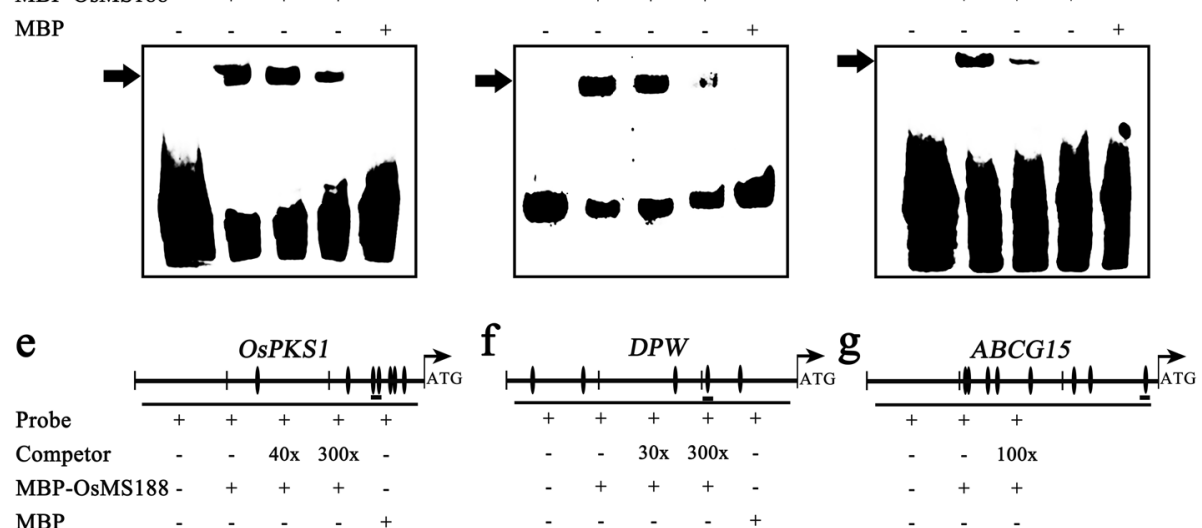

MBP
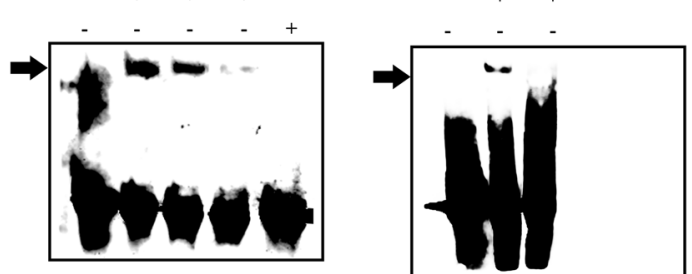

Fig. 7 OsMS188 directly regulates the expression of CYP703A3, CYP704B2, OsPKS2, OsPKS1, DPW and ABCG15. a QRT-PCR analysis of CYP703A3, CYP704B2, OsPKS2, OsPKS1, DPW and ABCG15 expression in the inflorescences in WT, osms188 and tdr backgrounds. b-g EMSAs showing that OsMS188 can bind to the fragments of the CYP703A3, CYP704B2, OsPKS2, OsPKS1, DPW and ABCG15 promoter regions. MBP-tagged proteins were mixed with a biotin-labelled probe, and unlabelled probes were used as competitors. The arrowhead indicates a shifted band. $\mathbf{h}$ Transient dualluciferase assays were performed in Arabidopsis leaf protoplasts. A p35S::NOS vector was used as a negative control. p35s.:.OsMS188nos and p35s:: TDRnos were transformed into protoplasts together with reporter plasmids. Three replicates were assessed, and the Y-axis shows the ratio of luciferase/Renilla. The errors bars indicate the SDs

increase (Fig. 7h). The results demonstrate that OsMS188 not only directly binds to the MYB regulatory elements of the CYP703A3, CYP704B2, OsPKS1, OsPKS2, DPW and ABCG15 promoters but also activates the expression of these genes.

\section{Discussion}

OsMS188 Plays Multiple Roles in Anther Development in Rice

A previous investigation showed that the downregulation of OsMS188 via an RNAi approach leads to reduced male fertility of transgenic plants (Zhang et al. 2010). In this study, we further characterized the detailed functions of OsMS188 in anther development and pollen formation through knock-out mutant analysis. We used the CRISPR-Cas9 technique to generate two complete male sterility-inducing alleles of the OsMS188 gene with a frame-shift mutation (Fig. 1). Cytological observations showed that the tapetal cells of osms188 exhibit an abnormal development phenotype with aberrant vacuolization (Fig. 2). Recently, a knockout line of OsMS188 was reported to exhibit premature tapetal cell death (Pan 
et al. 2020). Therefore, OsMS188/OsMYB80 is an essential regulator of tapetum development in rice. During anther development, the tapetum undergoes endomitosis and gradual apoptosis/programmed cell death (PCD) to complete its development and fulfil its function (Stevens and Murray 1981; Vizcay-Barrena and Wilson 2006). TUNEL assays showed that a weak fluorescence signal was detected in aberrant tapetal cells of the osms 188 mutant, suggesting that OsMS188 is involved in tapetal PCD progression (Fig. 3). PTC1 has been reported to control programmed tapetum development in rice ( $\mathrm{Li}$ et al. 2011) and to act as a downstream target of OsMS188 (Pan et al. 2020). Therefore, OsMS188 is likely to regulate tapetum programmed death through PTC1 during anther development.

The pollen wall protects the developing microspore through its resistance to external stresses and promotion of the identification and attachment of pollen to thestigma (Ariizumi et al. 2004). The cuticle layer on the anther surface plays an important role in protecting organisms against water loss, UV irradiation, and frost damage (Jung et al. 2006). In rice, sexine formation depends on the synthesis and modification of lipids, and the wax layer is composed of very-long-chain fatty acids. In rice, mutants of most pollen wall-related genes, including CYP703A3, CYP704B2, OsPKS1, OsPKS2, DPW, ABCG15, OsABCG26, DPW2, DPW3 and TKPR1, exhibit not only defective exine deposition but also abnormal formation of the wax layer on the anther surface ( $\mathrm{Li}$ et al. 2010; Shi et al. 2011; Qin et al. 2013; Yang et al. 2014; Zhao et al. 2015; Zhang et al. 2016; Xu et al. 2017; Zou et al. 2017; Shi et al. 2018; Zou et al. 2018; Xu et al. 2019; Mondol et al. 2020). In osms188, both the sexine layer around the pollen grains and the wax layer on the anther surface were absent (Fig. 2). Previous studies showed that the expression of CYP703A3 was downregulated in $t d r$ and $g a m y b$ mutants. TDR and GAMYB can bind to the promoter of CYP703A3 (Yang et al. 2014; Aya et al. 2009). However, it is not clear whether they can activate CYP703A3 expression. In this work, gene expression analysis showed that the expression of all of the above pollen wall-related genes was downregulated in osms 188 anthers, suggesting that they act downstream of OsMS188 (Fig. 7a; Fig. S3). EMSAs and protoplast dual-luciferase assays showed that OsMS188 not only directly bound to the promoters of CYP703A3, CYP704B2, OsPKS1, OsPKS2, DPW and ABCG15 but also activated their expression as a main-effect factor during pollen wall formation (Fig. 7). Considering the absence of the exine and cuticle layer in osms188, we propose that the transcriptional regulatory pathway for lipid synthesis in the tapetum is also shared with exine and anther cuticle formation in rice, although the transport mechanism remains unclear. Therefore, the sporopollenin synthesis pathway might be responsible for the formation of the pollen wall and anther cuticle at the same time in rice. OsMS188 plays multiple roles during anther development, including tapetum development, pollen wall formation and anther surface formation.

\section{The Transcriptional Regulatory Pathway of Rice Tapetum Development}

In rice, several transcription factors regulating tapetum development have been reported, including UDT1, OsTDF1, bHLH142/TIP2, TDR, EAT1 and PTC1 (Jung et al. 2005; Li et al. 2006; Li et al. 2011; Niu et al. 2013; Fu et al. 2014; Ko et al. 2014; Cai et al. 2015). The ablation of UDT1, OsTDF1, TDR and TIP2 leads to vacuolated and hypertrophic tapetal cells, suggesting that these genes are involved in early tapetum development (Jung et al. 2005; Li et al. 2006; Niu et al. 2013; Fu et al. 2014; Cai et al. 2015). In this study, we showed that the MYB transcription factor OsMS188 is strongly expressed in tapetal cells and acts as an essential regulator of their development and degradation (Fig. 3; Fig. 4). A previous study proposed a regulatory relationship among TDR, bHLH142 and EAT1 and suggested that these proteins regulate the downstream genes CYP703A3, CYP704B2 and OsC6 (Shi et al. 2015). This work and other studies (Cai et al. 2015; Pan et al. 2020) further expand the known regulatory network of tapetum development and functions (Fig. 8). This network includes two additional regulators: OsTDF1 and OsMS188. OsTDF1 acts downstream of UDT1 and upstream of TDR and EAT1 (Cai et al. 2015). Among these upstream regulators, TDR directly regulates OsMS188 (Fig. 5; Fig. S2), and OsMS188 directly regulates sporopollenin-related genes for pollen wall formation (Fig. 7). MYB family members frequently interact with bHLH transcription factors to regulate downstream gene expression (Koes et al. 2005; Appelhagen et al. 2011). Both $\mathrm{Y} 2 \mathrm{H}$ assays and EMSAs suggested that TDR interacted with OsMS188 to regulate downstream gene expression (Fig. 5; Fig. 6). Although TDR could bind to the promoter of sporopollenin related genes (Yang et al. 2014; Shi et al. 2015), transient dualluciferase assays showed that TDR is unlikely to directly activate the expression of these genes (Fig. 7h). We speculate that TDR regulates pollen wall formation by activating the expression of OsMS188 during anther development. Additionally, GAMYB and PTC2 have also been reported to regulate exine formation and $\mathrm{PCD}$ of tapetal cells in rice anther development (Aya et al. 2009; Uzair et al. 2020). PTC2 is the homologue of TEK, an AT-hook motif nuclear-localized protein essential for nexine formation in Arabidopsis. AMS (an orthologue of TDR) directly regulates TEK and MS188 expression for sexine and nexine formation (Lou et al. 2014). We 


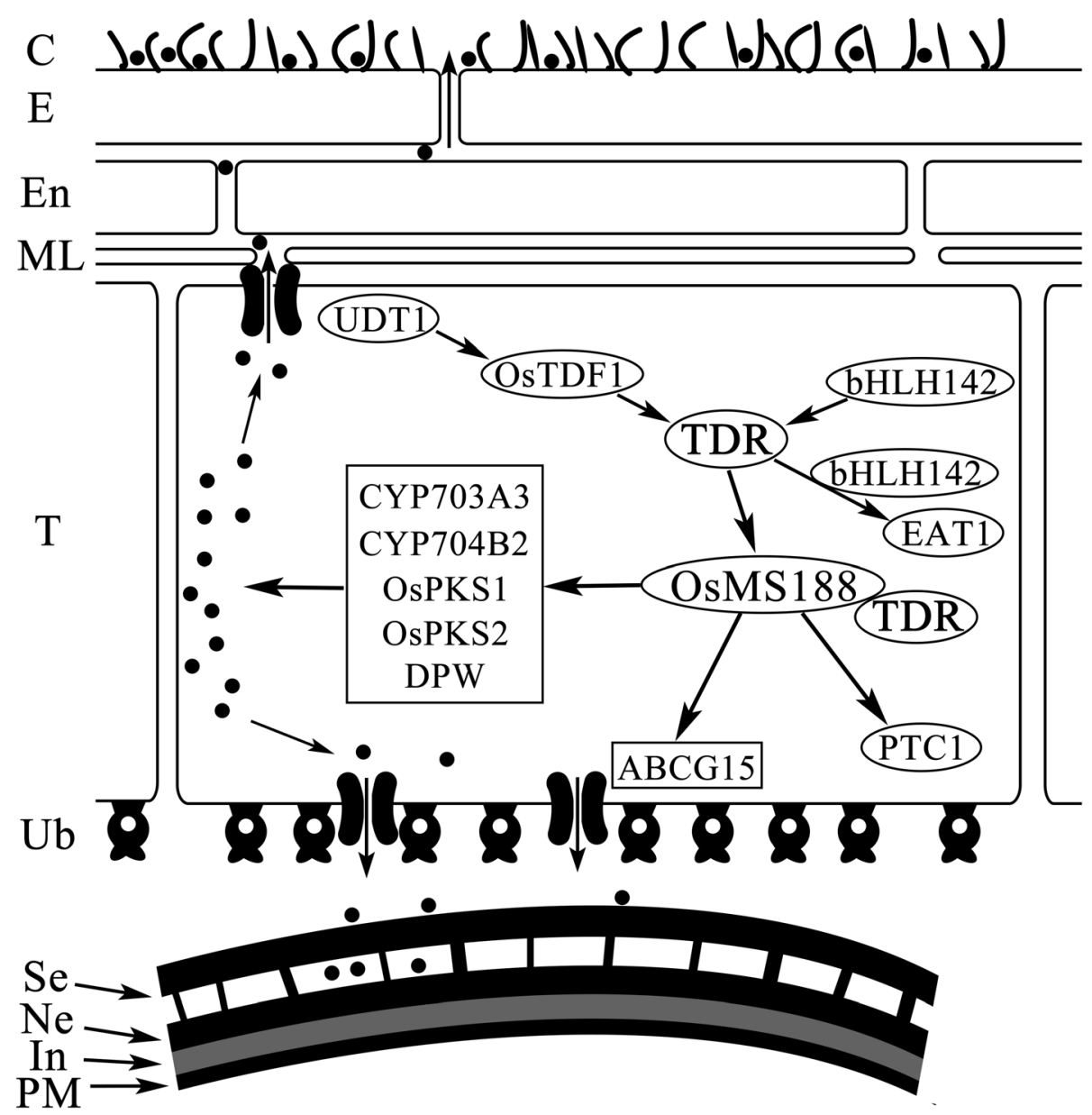

Fig. 8 Proposed model for rice tapetum-related gene regulatory network. In the genetic pathway of the rice tapetal layer, the oval circles represent transcription factors. The genes in the box represent downstream enzymes. The black arrows represent positive regulation, and the black dots represent lipid synthesis in tapetal cells. This model indicates that OsMS188 acts as a core hub to modulate tapetum development and pollen wall and cuticle formation. C, cuticle; E, epidermis; En, endothecium; In, intine; ML, middle layer; Ne, nexine; PM, plasma membrane; Se, sexine; T, tapetum; Ub, Ubisch body

propose that PTC2 and OsMS188 are parallel in the rice tapetal genetic pathway regulated by TDR. However, our $\mathrm{Y} 2 \mathrm{H}$ assays showed that they also did not interact with OsMS188 (Fig. S5). PTC1 is a regulator of late tapetum development, as the tapetum of ptc1 is aberrantly degenerated after meiosis ( $\mathrm{Li}$ et al. 2011), and PTC1 acts downstream of OsMS188 (Pan et al. 2020). Combined with the regulatory role of OsMS188 in the activation of sporopollenin synthesis, OsMS188 plays a central role in tapetum development, pollen formation and anther cuticle formation (Fig. 8). All the genes in this network are essential for anther development and pollen formation. Plants with mutations in these genes exhibit a male-sterile phenotype. This gene regulatory network will be helpful forfuture investigation of anther development as well as fertility regulation in rice.

\section{Materials and Methods}

Plant Materials and Growth Conditions

All the rice plants used in this study were grown in the botanical garden at Shanghai Normal University (Shanghai, China). The generation of the osms188-1 and osms188-2 mutants was mediated by CRISPR-Cas9 technology. The target sites in the osms188 coding sequence were identified with designer software and fused into the CRISPR-Cas9 plasmids. The constructed plasmids were subsequently introduced into Agrobacterium tumefaciens EHA105, which were then transformed into wild type Nipponbare rice.

\section{Phenotypic Analysis of the Mutant}

The plants were imaged with a Nikon D7000 digital camera (Nikon, Japan) and an Olympus SZX10 dissecting microscope (Olympus, Japan). Images of spikelets 
and anthers were captured with an Olympus BX51 fluorescence microscope (Olympus, Japan). Pollen viability was assessed using Alexander's solution for staining wild-type and mutant anthers. By the use of semi-thin sections along with SEM (JEOL, Japan) and TEM (Hitachi, Japan) observations, the spikelets and anthers of wild type and osms 188 mutant plants were classified as belonging to different stages to avoid experimental deviation. The embedding and observation procedures were performed as described in a previous study (Lou et al. 2014).

\section{TUNEL Assay}

Wild type and osms188 spikelets were fixed in FAA solution for 1 day at $4{ }^{\circ} \mathrm{C}$. The samples were then dehydrated through an ethanol gradient and xylene and embedded in paraffin (Sigma, USA). The embedding block was sectioned to a thickness of $7 \mu \mathrm{m}$ by an MR2 rotary microtome (RMC, USA) attached to Poly-Prep slides (Sigma, USA). The TUNEL apoptosis detection process was performed with a DeadEnd Fluorometric TUNEL system kit (Promega, USA) according to the product's instructions. Images were obtained using an Olympus FV3000 laser scanning microscope (Olympus, Japan).

\section{RNA In Situ Hybridization}

The embedding block of wild type spikelets was sectioned to a thickness of $8 \mathrm{~mm}$ using an MR2 rotary microtome (RMC, USA). A 415-bp specific fragment of the OsMS188 CDS was cloned into a pBluescript-SK vector (Stratagene, USA). Plasmid DNA was completely digested using EcoRI or HindIII. The antisense and sense probes of OsMS188 were transcribed using a digoxigenin (DIG) RNA labelling kit (Roche, Switzerland) according to the product's instructions. RNA hybridization and immunological detection of the hybridized probes were performed as described (Zhu et al. 2011, Shi et al. 2018). Afterward, the samples were imaged via an Olympus DP73 digital camera (Olympus, Japan).

\section{RT-PCR and qRT-PCR}

Total RNA was isolated from the spikelets of wild-type and osms 188 plants at different stages using a TRIzol kit (Invitrogen, USA). Reverse transcription was performed using TransScript Fly First-Strand cDNA Synthesis SuperMix (TransGen Biotech, China). The semiquantitative RT-PCR procedure was performed as described previously (Zhang et al. 2007). QRT-PCR analyses of each sample were performed in conjunction with SYBR Green Real-time PCR Master Mix (Toyobo, Japan) and an ABI 7300 system (Life Technologies, USA). The quantitative PCR procedure and conditions were the same as those previously described (Xiong et al. 2016). Actin was used as an internal control. Three biological replicates were performed for each experiment. The sequences of all the primers used are listed in Table S1.

\section{Electrophoretic Mobility Shift Assays (EMSAs)}

The full-length CDSs of OsMS188, TDR, bHLH142 and EAT1 were cloned into a pMAL-c5X vector (GE Healthcare, USA) to generate the MBP-OsMS188, MBP-TDR, MBP-bHLH142 and MBP-EAT1 constructs. The expression and purification of the fusion proteins were conducted according to the manufacturer's instructions. Labelled or unlabelled probes containing the core motifs of the OsMS188 binding sites of the CYP703A3, CYP704B2, OsPKS1, OsPKS2, DPW and ABCG15 promoters were generated by using specific primers (Table S1), and probes were also generated for TDR in OsMS188. A LightShift Chemiluminescent EMSA Kit (Thermo Scientific, USA) was used to perform the EMSAs. The resulting images were captured with a Tanon-5500 Chemiluminescent Imaging System.

\section{Dual-Luciferase Transient Expression Assays of Arabidopsis Protoplasts}

Protoplasts obtained from Arabidopsis (Col-0) leaves were grown for $21-28$ day and digested with $0.75 \%(w / v)$ cellulase R10 and $0.175 \%(\mathrm{w} / \mathrm{v})$ macerozyme R10 (Yakult Honsha, Tokyo). The plasmids $p 35 S:: T D R-n o s$ and $p 35 S::$ OsMS188CDS-nos and the pGreenII 0800-LUC vector containing the promoters of OsMS188, CYP703A3, CYP704B2, OsPKS1, OsPKS2, DPW and ABCG15 were cotransformed into protoplasts mediated by $40 \%(\mathrm{w} / \mathrm{v})$ PEG4000 and cultivated overnight. After lysing the protoplasts by the addition of passive lysis buffer, firefly and Renilla luciferase activities were quantified using a DualLuciferase Reporter Assay System (Promega, USA) and detected with a GloMax Navigator Microplate Luminometer (Promega, USA), according to the manufacturers' instructions.

\section{Phylogenetic Analysis}

The homologous protein of OsMS188 in Arabidopsis thaliana was identified using the Basic Local Alignment Search Tool (BLAST) of the National Center for Biotechnology Information (http://www.ncbi.nlm.nih.gov/). Multiple sequence alignments of the full-length protein sequences were performed using Clustal $\mathrm{W}$ and displayed using BoxShade (http://www.ch.embnet.org/ software/ClustalW.html).

\section{Yeast Two-Hybrid Assays}

The yeast two-hybrid assays were performed following the protocol of a Clontech two-hybrid system (Clontech, USA). The CDSs of OsMS188 (different lengths) were amplified and fused into pGBKT7 plasmids to determine 
the self-activation domain. Similarly, the coding sequences of TDR, GAMYB and PTC2 were inserted into pGADT7 plasmids. These constructs were cotransformed into the AH109 yeast strain that was screened under selective growth conditions as described in a previous study (Xiong et al. 2016).

\section{LCl Assays}

The coding sequences of OsMS188 and OsTDR were cloned into JW771-NLUC and JW772-CLUC, respectively. LCI assays were performed as described in previous studies (Zhang et al. 2015; Wang et al. 2019). Agrobacterium tumefaciens (strain GV3101 with pSoupp19 vector) containing the recombinant plasmid was infiltrated into Nicotiana benthamiana leaves via needleless syringes.

\section{Supplementary Information}

The online version contains supplementary material available at https://doi. org/10.1186/s12284-020-00451-y.

Additional file 1: Table S1. Sequences of primers used in this study. Additional file 2: Fig. S1. Semi-thin sections of the wild type and osms 188 mutant. Bars $=20 \mu \mathrm{m}$.

Additional file 3: Fig. S2. RT-PCR analysis of the expression of OSMS188 in inflorescences of WT, udt1, ostdf1, tdr, bhlh142 and eat1 after 30 and 35 cycles. gDNA: genomic DNA.

Additional file 4: Fig. S3. QRT-PCR analysis of the expression of DPW2, DPW3, TKPR1 and OSABCG26 in inflorescences of the osms188 mutant.

Additional file 5: Fig. S4. The OsMS188 protein was expressed and purified from Rosetta Escherichia coli. The black box indicates the target band.

Additional file 6: Fig. S5. $\mathrm{Y} 2 \mathrm{H}$ assay showing that OsMS188 cannot interact with GAMYB or PTC2.

\section{Abbreviations}

EMSAs: Electrophoretic mobility shift assays; LCl: Luciferase complementation imaging; LUC: Luciferase; MBP: Maltose binding protein; GRT-

PCR: Quantitative real-time PCR; RT-PCR: Reverse transcription-PCR;

SEM: Scanning electron microscopy; TEM: Transmission electron microscopy; TUNEL: Terminal deoxynucleotidyl transferase-mediated dUTP nick-end labelling; WT: Wild-type; Y2H: Yeast two-hybrid

\section{Acknowledgements}

We thank Chandrashekhar Joshi for revising the manuscript.

\section{Authors' Contributions}

Z.Y., J.Z. and Y.H. designed the project. Y.H., S.Z., J.F., L.Z., Q.S., Y.Z., X.L. and X.C. performed the experiments. Y.H. and S.Z. analyzed the data. Z.Y., J.Z. and Y.H. wrote the manuscript. All authors had read and approved the manuscript.

\section{Funding}

This work was funded by National Science Foundation of China (31930009, 31770348), and the Innovation Programme of the Shanghai Municipal Education Commission (2019-01-07-00-02-E00006).

\section{Availability of Data and Materials}

All data generated or analyzed during this study are included in this published article and its supplementary information files.

Ethics Approval and Consent to Participate

No applicable.
Consent for Publication

No applicable.

\section{Competing Interests}

The authors declare that they have no competing interests.

Received: 7 June 2020 Accepted: 26 December 2020

Published online: 06 January 2021

\section{References}

Appelhagen I, Jahns O, Bartelniewoehner L, Sagasser M, Weisshaar B, Stracke R (2011) Leucoanthocyanidin Dioxygenase in Arabidopsis thaliana: characterization of mutant alleles and regulation by MYB-BHLH-TTG1 transcription factor complexes. Gene 484(1-2):61-68

Ariizumi T, Hatakeyama K, Hinata K, Inatsugi R, Nishida I, Sato S, Kato T, Tabata S, Toriyama K (2004) Disruption of the novel plant protein NEF1 affects lipid accumulation in the plastids of the tapetum and exine formation of pollen, resulting in male sterility in Arabidopsis thaliana. Plant J 39(2):170-181

Ariizumi T, Toriyama K (2011) Genetic regulation of sporopollenin synthesis and pollen exine development. Annu Rev Plant Biol 62:437-460

Aya K, Ueguchi-Tanaka M, Kondo M, Hamada K, Yano K, Nishimura M, Matsuoka M (2009) Gibberellin modulates anther development in rice via the transcriptional regulation of GAMYB. Plant Cell 21(5):1453-1472

Cai CF, Zhu J, Lou Y, Guo ZL, Xiong SX, Wang K, Yang ZN (2015) The functional analysis of OsTDF1 reveals a conserved genetic pathway for tapetal development between rice and Arabidopsis. Sci Bull 60(12):1073-1082

Chen LT, Liu YG (2014) Male sterility and fertility restoration in crops. Annu Rev Plant Biol 65:579-606

Fu ZZ, Yu J, Cheng XW, Zong X, Xu J, Chen MJ, Li ZY, Zhang DB, Liang WO (2014) The Rice basic helix-loop-helix transcription factor TDR INTERACTING PROTEIN2 is a central switch in early anther development. Plant Cell 26(4): 1512-1524

Ji CH, Li HY, Chen LB, Xie M, Wang FP, Chen YL, Liu YG (2013) A novel Rice bHLH transcription factor, DTD, acts coordinately with TDR in controlling Tapetum function and pollen development. Mol Plant 6(5):1715-1718

Jung KH, Han MJ, Lee DY, Lee YS, Schreiber L, Franke R, Faust A, Yephremov A, Saedler H, Kim YW, Hwang I, An G (2006) Wax-deficient anther1 is involved in cuticle and wax production in rice anther walls and is required for pollen development. Plant Cell 18(11):3015-3032

Jung KH, Han MJ, Lee YS, Kim YW, Hwang I, Kim MJ, Kim YK, Nahm BH, An G (2005) Rice undeveloped Tapetum 1 is a major regulator of early tapetum development. Plant Cell 17(10):2705-2722

Ko SS, Li MJ, Sun-Ben Ku M, Ho YC, Lin YJ, Chuang MH, Hsing HX, Lien YC, Yang HT, Chang HC, Chan MT (2014) The bHLH142 transcription factor coordinates with TDR1 to modulate the expression of EAT1 and regulate pollen development in rice. Plant Cell 26(6):2486-2504

Koes R, Verweij W, Quattrocchio F (2005) Flavonoids: a colorful model for the regulation and evolution of biochemical pathways. Trends Plant Sci 10(5): 236-242

Li H, Pinot F, Sauveplane V, Werck-Reichhart D, Diehl P, Schreiber L, Franke R, Zhang P, Chen L, Gao YW, Liang WQ, Zhang DB (2010) Cytochrome P450 family member CYP704B2 catalyzes the \{0mega\}-hydroxylation of fatty acids and is required for anther cutin biosynthesis and pollen exine formation in rice. Plant Cell 22(1):173-190

Li H, Yuan Z, Vizcay-Barrena G, Yang CY, Liang WQ, Zong J, Wilson ZA, Zhang DB (2011) PERSISTENT TAPETAL CELL1 encodes a PHD-finger protein that is required for tapetal CELL death and pollen development in rice. Plant Physiol 156(2):615-630

Li N, Zhang DS, Liu HS, Yin CS, Li XX, Liang WQ, Yuan Z, Xu B, Chu HW, Wang J, Wen TQ, Huang H, Luo D, Ma H, Zhang DB (2006) The rice tapetum degeneration retardation gene is required for tapetum degradation and anther development. Plant Cell 18(11):2999-3014

Li YL, Li DD, Guo ZL, Shi QS, Xiong SX, Zhang C, Zhu J, Yang ZN (2016) OsACOS12, an orthologue of Arabidopsis acyl-CoA synthetase5, plays an important role in pollen exine formation and anther development in rice. BMC Plant Biol 16:256

Lou Y, Xu XF, Zhu J, Gu JN, Blackmore S, Yang ZN (2014) The tapetal AHL family protein TEK determines nexine formation in the pollen wall. Nat Commun 5: 3855 
Mariani C, Beuckeleer MD, Truettner J, Leemans J, Goldberg RBJN (1990) Induction of male-sterility in plants by a chimeric ribonuclease gene. Nature 347(6295):737-741

McCormick S (1993) Male gametophyte development. Plant Cell 5(10):1265-1275

Mondol PC, Xu DW, Duan L, Shi JX, Wang CH, Chen XF, Chen MJ, Hu JP, Liang WQ, Zhang DB (2020) Defective Pollen Wall 3 (DPW3), a novel alpha integrinlike protein, is required for pollen wall formation in rice. New Phytol 225(2): 807-822

Niu NN, Liang WQ, Yang XJ, Jin WL, Wilson ZA, Hu JP, Zhang DB (2013) EAT1 promotes tapetal cell death by regulating aspartic proteases during male reproductive development in rice. Nat Commun 4:1445

Pan X, Yan W, Chang Z, Xu Y, Luo M, Xu C, Chen Z, Wu J, Tang X (2020) OsMYB80 regulates anther development and pollen fertility by targeting multiple biological pathways. Plant Cell Physiol. https://doi.org/10.1093/pcp/ pcaa025

Qin P, Tu B, Wang YP, Deng LC, Quilichini TD, Li T, Wang H, Ma BT, Li SG (2013) $A B C G 15$ encodes an $A B C$ transporter protein, and is essential for postmeiotic anther and pollen Exine development in Rice. Plant Cell Physiol 54(1):138-154

Shi J, Cui M, Yang L, Kim YJ, Zhang D (2015) Genetic and biochemical mechanisms of pollen wall development. Trends Plant Sci 20(11):741-753

Shi J, Tan HX, Yu XH, Liu YY, Liang WQ, Ranathunge K, Franke RB, Schreiber L, Wang YJ, Kai GY, Shanklin J, Ma H, Zhang DB (2011) Defective Pollen Wall is required for anther and microspore development in rice and encodes a fatty acyl carrier protein reductase. Plant Cell 23(6):2225-2246

Shi QS, Wang KQ, Li YL, Zhou L, Xiong SX, Han Y, Zhang YF, Yang NY, Yang ZN, Zhu J (2018) OsPKS1 is required for sexine layer formation, which shows functional conservation between rice and Arabidopsis. Plant Sci 277:145-154

Stevens VA, Murray BG (1981) Studies on heteromorphic self-incompatibility systems: the cytochemistry and ultrastructure of the tapetum of Primula obconica. J Cell Sci 50:419-431

Uzair M, Xu DW, Schreiber L, Shi JX, Liang WQ, Jung KH, Chen MJ, Luo ZJ, Zhang YY, Yu J, Zhang DB (2020) PERSISTENT TAPETAL CELL2 is required for Normal Tapetal programmed CELL death and Pollen Wall patterning. Plant Physiol 182(2):962-976

Vizcay-Barrena G, Wilson ZA (2006) Altered tapetal PCD and pollen wall development in the Arabidopsis ms1 mutant. J Exp Bot 57(11):2709-2717

Wang AH, Hou QQ, Si LZ, Huang XH, Luo JH, Lu DF, Zhu JJ, Shangguan YY, Miao JS, Xie YF, Wang YC, Zhao Q, Feng Q, Zhou CC, Li Y, Fan DL, Lu YQ, Tian QL, Wang ZX, Han B (2019) The PLATZ transcription factor GL6 affects grain length and number in Rice. Plant Physiol 180(4):2077-2090

Wu L, Guan Y, Wu Z, Yang K, Lv J, Converse R, Huang Y, Mao J, Zhao Y, Wang Z, Min H, Kan D, Zhang Y (2014) OsABCG15 encodes a membrane protein that plays an important role in anther cuticle and pollen exine formation in rice. Plant Cell Rep 33(11):1881-1899

Xiong SX, Lu JY, Lou Y, Teng XD, Gu JN, Zhang C, Shi QS, Yang ZN, Zhu J (2016) The transcription factors MS188 and AMS form a complex to activate the expression of CYP703A2 for sporopollenin biosynthesis in Arabidopsis thaliana. Plant J 88(6):936-946

Xu DW, Qu SY, Tucker MR, Zhang DB, Liang WQ, Shi JX (2019) Ostkpr1 functions in anther cuticle development and pollen wall formation in rice. BMC Plant Biol 19(1):104

Xu DW, Shi JX, Rautengarten C, Yang L, Qian XL, Uzair M, Zhu L, Luo Q, An G, Wassmann F, Schreiber L, Heazlewood JL, Scheller HV, Hu J, Zhang DB, Liang WQ (2017) Defective Pollen Wall 2 (DPW2) encodes an acyl Transferase required for Rice pollen development. Plant Physiol 173(1):240-255

Yang X, Liang WQ, Chen M, Zhang DB, Zhao X, Shi JX (2017) Rice fatty acyl-CoA synthetase OsACOS12 is required for tapetum programmed cell death and male fertility. Planta 246(1):105-122

Yang XJ, Wu D, Shi JX, He Y, Pinot F, Grausem B, Yin CS, Zhu L, Chen MJ, Luo ZJ, Liang WQ, Zhang DB (2014) Rice CYP703A3, a cytochrome P450 hydroxylase, is essential for development of anther cuticle and pollen exine. J Integr Plant Biol 56(10):979-994

Zhang DB, Shi JX, Yang XJ (2016) Role of lipid metabolism in plant pollen Exine development. In: lipids in plant and algae development. Subcellular biochem 86. Springer, New York:315-337

Zhang DB, Wilson ZA (2009) Stamen specification and anther development in rice. Chin Sci Bull 54(14):2342-2353

Zhang S, Fang ZJ, Zhu J, Gao JF, Yang ZN (2010) OsMYB103 is required for rice anther development by regulating tapetum development and exine formation. Chin Sci Bull 55(29):3288-3297
Zhang ZB, Zhu J, Gao JF, Wang C, Li H, Li H, Zhang HQ, Zhang S, Wang DM, Wang QX, Huang H, Xia HJ, Yang ZN (2007) Transcription factor AtMYB103 is required for anther development by regulating tapetum development, callose dissolution and exine formation in Arabidopsis. Plant J 52(3):528-538

Zhang ZY, Yang J, Wu YR (2015) Transcriptional regulation of zein gene expression in maize through the additive and synergistic action of opaque2, Prolamine-box binding factor, and $\mathrm{O} 2$ heterodimerizing proteins. Plant Cell 27(4):1162-1172

Zhao GC, Shi JX, Liang WQ, Xue FY, Luo Q, Zhu L, Qu GR, Chen MJ, Schreiber L, Zhang DB (2015) Two ATP binding cassette $G$ transporters, rice ATP binding cassette G26 and ATP binding cassette G15, collaboratively regulate rice male reproduction. Plant Physiol 169(3):2064-2079

Zhu J, Lou Y, Xu XF, Yang ZN (2011) A genetic pathway for tapetum development and function in Arabidopsis. J Integr Plant Biol 53(11):892-900

Zou T, Liu M, Xiao Q, Wang T, Chen D, Luo T, Yuan G, Li Q, Zhu J, Liang Y, Deng Q, Wang S, Zheng A, Wang L, Li P, Li S (2018) OsPKS2 is required for rice male fertility by participating in pollen wall formation. Plant Cell Rep 37(5): 759-773

Zou T, Xiao Q, Li WJ, Luo T, Yuan GQ, He ZY, Liu MX, Li Q, Xu PZ, Zhu J, Liang YY, Deng QM, Wang SQ, Zheng AP, Wang LX, Li P, Li SC (2017) OsLAP6/OsPKS1, an orthologue of Arabidopsis PKSA/LAP6, is critical for proper pollen exine formation. Rice 10:53

\section{Publisher's Note}

Springer Nature remains neutral with regard to jurisdictional claims in published maps and institutional affiliations.

\section{Submit your manuscript to a SpringerOpen ${ }^{\circ}$ journal and benefit from:}

- Convenient online submission

- Rigorous peer review

- Open access: articles freely available online

High visibility within the field

- Retaining the copyright to your article

Submit your next manuscript at $\boldsymbol{\sim}$ springeropen.com 